\title{
III.33 Monitoring and compliance mechanisms
}

\author{
Antonio Cardesa-Salzmann
}

Lecturer, Strathclyde Centre for Environmental Law and Governance, University of

Strathclyde, Glasgow, United Kingdom

\begin{abstract}
This chapter provides a general perspective of monitoring and compliance mechanisms in multilateral environmental agreements related to the protection of biodiversity. Starting with the specificities that explain the emergence of endogenous enforcement solutions in these sorts of treaty, it makes a conceptual distinction between monitoring and compliance mechanisms. On this basis, it appraises their institutional design and procedural outline, as well as the nature of the measures that these mechanisms issue in order to elicit compliance and enforce treaty obligations. It concludes with an overall assessment of these mechanisms' performance, providing a final reflection on new and remaining research directions.
\end{abstract}

\section{Keywords}

Biodiversity and nature protection regimes, biodiversity-related conventions, monitoring, compliance mechanisms

\section{Contents}

III.33.1 Introduction

III.33.2 Monitoring and compliance mechanisms in biodiversity regimes: common features

III.33.2.1 Monitoring

III.33.2.2 Compliance mechanisms

III.33.3 Institutional design of compliance bodies

III.33.4 Procedural aspects and compliance mechanisms

III.33.4.1 Initiation of non-compliance procedures

III.33.4.2 Public participation

III.33.4.3 Compliance measures

III.33.5 Final remarks

III.33.6 Annex: list of compliance measures adopted in biodiversity and nature protection treaties

III.33.6.1 Compliance mechanisms in the biodiversity regime 
III.33.6.2 Compliance mechanisms in sectorial or issue-specific diversity and nature protection regimes

III.33.6.3 Compliance mechanisms in Regional Fisheries Management Organizations

\section{III.33.1 Introduction}

International law looks back to a significant tradition of customary and, especially, conventional rules regarding the protection of specific forms of wildlife and the conservation of nature. Since the early twentieth century, a series of multilateral treaties have channelled the efforts of states to ensure the conservation of species, groups thereof, and habitats. The regulatory approaches underlying these international legal rules, however, have evolved over time from anthropocentric utilitarianism to the sustainable management of living resources based on ecosystem approaches. ${ }^{1}$ The 1971 Ramsar Convention on Wetlands of International Importance spearheaded this latter regulatory paradigm for wildlife or nature protection law, which nevertheless continued to evolve towards a more holistic approach. Indeed, the growing scientific acknowledgment of the intrinsic interconnectedness of all life on Earth eventually provoked a paradigmatic shift away from the protection of specific species, habitats or ecosystems, to the conservation and sustainable use of biological resources at large and their diversity. ${ }^{2}$ Already announced in the 1982 World Charter for Nature, ${ }^{3}$ this new approach found its consecration in the 1992 Convention on Biological Diversity ${ }^{4}$ (CBD) that pursues the triple objective of promoting the conservation and sustainable use of the components of biological diversity, while ensuring a fair and equitable sharing of benefits and charges derived from the utilization of genetic resources. ${ }^{5}$

It follows that biodiversity designates a field of international legal regulation that encompasses various layers of rules and regimes that emerged in different historical moments, according to disparate ideological premises and regulatory approaches. Nevertheless, to the extent that they deal with the conservation and use of biological

\footnotetext{
${ }^{1}$ Maffei (1993) 134ff.

${ }^{2}$ Rayfuse (2007) 365. More generally, also Bowman (1996).

${ }^{3}$ UN Doc A/RES/37/7 (28 October 1982).

${ }^{4}$ Convention on Biological Diversity (adopted 5 June 1992, entered into force 29 December 1993) 1760 UNTS 79 (CBD).

${ }^{5} \mathrm{CBD}$ art 1.
} 
resources, these regimes are all interrelated and, in a way, harnessed through the CBD. Relevant international regimes include, thus, much more than just the regime established by the CBD and developed by the 2000 Cartagena Protocol on Biosafety ${ }^{6}$ and the 2010 Nagoya Protocol on Access and Benefit Sharing. ${ }^{7}$ They also include the so-called biodiversity-related conventions, namely: the aforementioned Ramsar Convention, the 1972 World Heritage Convention (WHC), the 1973 CITES, the 1979 Convention on Migratory Species, the 1951 International Plant Protection Convention and the 2001 International Treaty on Plant Genetic Resources for Food and Agriculture (ITPGRFA). ${ }^{8}$ More generally, however, biodiversity regimes potentially encompass any regime regulating the harvest of species or genetic resources, the protection of habitats and/or different aspects of international trade with biological resources, so as to promote the sustainable management of direct and indirect threats to biodiversity. ${ }^{9}$ Such a broad definition also includes, for example, Regional Fishery Management Organizations (RFMOs). ${ }^{10}$

Arguably, despite disparate regulatory approaches, techniques and measures, all aforementioned biodiversity regimes converge in that their ultimate objective is of "common concern of humankind'. ${ }^{11}$ This specific feature poses concrete problems to their enforcement under international law that has led to the emergence of particular solutions. ${ }^{12}$ These typically consist of monitoring and compliance mechanisms. This chapter will provide an overview thereof, paying particular attention to the specificities that these mechanisms have developed in biodiversity regimes.

\section{III.33.2 Monitoring and compliance mechanisms in biodiversity regimes: common features}

\section{III.33.2.1 Monitoring}

Endogenous compliance review in international environmental regimes relies fundamentally on monitoring and verification: this mechanism aims at ascertaining the states' behaviour and

\footnotetext{
${ }^{6}$ See Chapter 16 in this volume.

${ }^{7}$ See Chapter 17 in this volume.

${ }^{8}$ See Chapters $7-8$ and 18 in this volume.

${ }^{9}$ Rayfuse (2007).

${ }^{10}$ See Chapter 9 in this volume.

${ }^{11}$ CBD Preamble para 3. See Chapter 2 in this volume.

12 Fitzmaurice (1994) 182-183.
} 
compliance with their international legal commitments. ${ }^{13}$ It fosters transparency and mutual trust between the parties and provides continuous feedback on the regimes' implementation and effectiveness. It is also crucial for managing compliance ${ }^{14}$ and, more generally, for the development of environmental regimes as on-going systems of governance. ${ }^{15}$

Monitoring relies primarily on regular national reporting according to guidelines prepared by the treaty bodies for a given period. The effectiveness of these mechanisms depends on a series of factors, most significantly the actual international commitments that are scrutinized (e.g., strict quantitative quotas of catches under RFMOs or diffuse and qualitative obligations under the CBD), the administrative and financial capacity of the parties (especially among developing countries) and the degree of institutionalization of each regime to deal with reporting and monitoring. ${ }^{16}$ Over the past decades a general trend towards the improvement of reporting has been observed, as well as an increased maturity of institutional arrangements for monitoring across international environmental treaties. ${ }^{17}$ Even though, admittedly, biodiversity regimes do not belong to the avant-garde of this development, the remarkable efforts made have led to a modest increase in the completeness and quality of reporting exercises. For example, out of 196 states parties to the CBD, its Secretariat received 151 national reports in the first reporting exercise, from where the number decreased to 137 in the following period. From this all-time low, compliance with reporting requirements recovered gradually and reached a high of 179 received reports in the fourth exercise. In the fifth exercise, due by March 2014, 151 reports have been received so far, although this number may still rise in the near future. ${ }^{18}$

One recurrent complaint by states is the sheer amount of reporting requirements under the whole range of global and regional multilateral environmental agreements (MEA). Occasionally, moreover, reporting requirements of interrelated regimes — as in the field of biodiversity — might be overlapping. In this sense, the harmonization of reporting requirements under biodiversity-related conventions has long been discussed. The options range from joint thematic reporting, as already taking place between the CBD and the Ramsar

\footnotetext{
${ }^{13}$ Wettestad (2007) 975.

${ }^{14}$ Chayes and Handler Chayes (1995).

15 Bodansky (1999) 604.

16 Wettestad (2007) 978.

17 ibid 982-985.

${ }^{18}$ Data from https://www.cbd.int/reports/ (accessed 31 July 2015).
} 
Convention, ${ }^{19}$ and a reporting system based on a core report relevant for all treaties involved, supplemented by smaller treaty-specific reports that address the specific information needs of the MEAs involved. ${ }^{20}$

Beyond weak and incomplete compliance with reporting requirements, however, the fundamental Achilles heel of monitoring in most biodiversity-related conventions is the difficulty of submitting the data obtained through official national reports to independent verification. The outstanding exception in this regard takes place in the context of CITES, where national reports submitted to the Secretariat are systematically scrutinized by TRAFFIC, ${ }^{21}$ an NGO that operates in close coordination with the CITES Secretariat and national CITES authorities. ${ }^{22}$

\section{III.33.2.2 Compliance mechanisms}

In addition to monitoring, a series of biodiversity regimes have also established compliance mechanisms. These have been typically designed to address individual compliance issues. Operated within the regimes' institutional arrangements ${ }^{23}$ through a cooperative and nonconfrontational procedure, these mechanisms are meant to identify the particular causes of a party's difficulties in order to provide bespoke support. Rather than following a punitive approach, their fundamental aim is to 'manage' arising issues and elicit compliance. ${ }^{24}$ This managerial approach, however, has also been questioned as leaving compliance with international obligations to the discretion of states and international institutions. ${ }^{25}$

Nevertheless, compliance mechanisms are also portrayed as optimized for the specific enforcement necessities of MEAs, providing one of the largely overlooked success stories of international environmental law in the recent past. ${ }^{26}$ By managing specific compliance issues, they avoid the emergence of disputes and, thus, the resort to adjudication. ${ }^{27}$ In fact,

\footnotetext{
${ }^{19}$ UNEP-WCMC (2009) 6. See also CBD-Ramsar 5th Joint Work Programme 2011-2020, http://ramsar.rgis.ch/pdf/moc/CBD-Ramsar5thJWP_2011-2020.pdf 4 (accessed 31 July 2015). 20 ibid.

21 This acronym stands for Trade Records Analysis of Flora and Fauna in Commerce (TRAFFIC).

${ }^{22}$ Wettestad (2007) 980.

${ }^{23}$ Churchill and Ulfstein (2000).

${ }^{24}$ Handl (1997) 34.

${ }^{25}$ Klabbers (2008) 349-50.

${ }^{26}$ French (2009) 283.

${ }^{27}$ Francioni (2003).
} 
compliance mechanisms are conceived of as entirely independent from (and potentially complementary to) adjudicative dispute settlement. ${ }^{28}$ Furthermore, being operated collectively within the MEA, they evade the delicate question of the invocation of state responsibility. ${ }^{29}$ Lastly, compliance mechanisms are ideal to enforce dynamic environmental regimes, in which the basic legally binding treaty-based principles and rules are fleshed out through decisions of the Conference of the Parties, the legal nature of which is not always easily determined. ${ }^{30}$

Within biodiversity law, compliance mechanisms have been established under the CBD regime, namely, under the Cartagena and Nagoya Protocols. Similar mechanisms have also been developed under the Ramsar Convention, the WHC, CITES, the 1979 Convention on the Conservation of European Wildlife and Natural Habitats (hereinafter, the Bern Convention), the 1976 Barcelona Convention for the Protection of the Marine Environment and the Coastal Region of the Mediterranean (as amended in 1995), the 1980 Convention on the Conservation of Antarctic Marine Living Resources, the 1991 Alpine Convention, and the ITPGRFA. Finally, as regards RFMOs, compliance mechanisms have also been enacted in the 1966 International Commission for the Conservation of Atlantic Tunas, the 1999 Agreement on the International Dolphin Conservation Programme, the 2000 Convention on the Conservation and Management of Highly Migratory Fish Stocks in the Western and Central Pacific Ocean, as well as in the 2003 Convention for the Strengthening of the InterAmerican Tropical Tuna Commission. ${ }^{31}$

The remaining sections will sketch out the common attributes and current developments regarding the institutional and procedural features of these mechanisms, as well as the compliance measures that they issue, before concluding with a general assessment of their performance.

\section{III.33.3 Institutional design of compliance bodies}

Conceived of as regime-specific compliance management tools, these mechanisms' institutional arrangements are fine-tuned to the particular enforcement necessities of each

\footnotetext{
${ }^{28}$ On the relationship between compliance mechanisms and adjudicative dispute settlement, see Fitzmaurice and Redgwell (2000); Treves (2009); Scott (2012) 254; and Boyle and Harrison (2013).

${ }^{29}$ Nègre (2010) 810.

${ }^{30}$ Klabbers (2007) 1008. Also Wiersema (2009).

${ }^{31}$ See section 6 below.
} 
treaty. There are, however, a series of homogenous features regarding their composition, functions and powers. ${ }^{32}$

Compliance mechanisms are generally entrusted to small-sized standing committees that are subsidiary bodies of the Conference of the Parties. ${ }^{33}$ Members act, depending on the mechanism's terms of reference, either as governmental representatives, or as independent experts in the best interest of the treaty. The states' choice either for a predominantly political compliance mechanism, or - as is increasingly the case - for an independent body of experts, depends on various factors. ${ }^{34}$ One is obviously the sensitivity of the interests at stake in a given regime. Another one is the soft or facilitative versus the hard or punitive powers that may be conferred to this mechanism. In either case, however, according to the underlying managerial rationale, compliance mechanisms remain under the ultimate political control of the Conference of the Parties. ${ }^{35}$

In order to ensure the legitimacy of their decisions, the terms of reference of compliance mechanisms also put special emphasis on the geographical balance among the members of the compliance body and the due representation of the views of developed, as well as developing countries. ${ }^{36}$ Members of the committee are supposed to have scientific, technical or legal expertise in areas relevant to the regime. Other criteria may also be taken into consideration depending on the interests at stake in a given regime. So, a balanced crosscultural representation is sought for the World Heritage Committee. ${ }^{37}$ In the new Nagoya Protocol compliance mechanism, members may include representatives of indigenous and local communities. ${ }^{38}$ Similarly, the International Dolphin Conservation Programme's International Review Panel has three representatives from specialized NGOs and from the tuna industry, respectively, among its members, alongside state representatives. ${ }^{39}$

Regarding the functions of compliance bodies, all of them review individual cases of noncompliance. Additionally, they may also be conferred the function of examining systemic

\footnotetext{
${ }^{32} \operatorname{Scott}(2012) 235 \mathrm{ff}$.

${ }^{33}$ In compliance bodies in RFMOs, however, all states parties are represented, ibid 236.

${ }^{34}$ Fodella (2009) 359-365.

35 ibid.

36 ibid.

${ }^{37}$ WHC art 8(2).

${ }^{38}$ UN Doc UNEP/CBD/NP/COP-MOP/DEC/1/4 (2014) Annex para B.2.

391999 Agreement on the International Dolphin Conservation Programme Annex VII para 2.
} 
issues of general non-compliance. ${ }^{40}$ Decisions within compliance bodies are commonly adopted by consensus and, alternatively, by a qualified majority. Only in the Standing Committee of CITES are decisions taken by a simple majority. ${ }^{41}$

\section{III.33.4 Procedural aspects and compliance measures}

Compliance mechanisms are operated through non-compliance procedures (NCPs) that share a common set of features. In contrast to international adjudication, they are designed as flexible, cooperative and non-confrontational procedures that elicit compliance through bespoke assistance. In specific regimes, moreover, sanctions may be adopted as a last resort, mainly in the form of the suspension of the rights and privileges of the defaulting party. Within biodiversity regimes, this is particularly the case with CITES, the NCP of which has been portrayed as 'a system of multilateral retorsion'. ${ }^{42}$

\section{$<b>$ III.33.4.1 Initiation of non-compliance procedures}

NCPs may be initiated on a party-to-party basis. However, what makes out their cooperative and non-adversarial idiosyncrasy is the capacity of the parties to submit any compliance issue with respect to themselves, as well as the capacity of treaty bodies (typically, the Secretariat), to trigger the procedure in defence of the common interest. However, a comparative approach reveals that this latter trigger mechanism is only fully operative in environmental regimes featuring erga omnes partes obligations. ${ }^{43}$ Again, the exception is CITES. Under its National Legislation Project, the Secretariat scrutinizes implementing laws from all parties according to four criteria-whether they designate at least one Management Authority and one Scientific Authority; whether they prohibit trade in specimens in violation of CITES; whether they penalize such trade; and whether they confiscate specimens illegally-traded or possessed. Thereafter, countries are classified either as countries having legislation that is believed generally to meet the requirements for implementation of CITES (category 1), as countries that are believed generally not to meet all of the requirements (category 2) or as

\footnotetext{
${ }^{40}$ For the Cartagena Protocol compliance mechanism, see COP-MOP Dec BS-I/7 Annex para III. UN Doc UNEP/CBD/BS/COP-MOP/1/15 (2004). For the Nagoya Protocol compliance mechanism, see COP-MOP Dec NP-1/4 para D.11.

${ }^{41}$ CITES Resolution Conf. 11.1 (Rev. CoP16)-Annex 1.

${ }^{42}$ Sand (2013) 254.

${ }^{43}$ Cardesa-Salzmann (2012) 115-121.
} 
countries that are believed generally not to meet any of the requirements (category 3 ). ${ }^{44}$ This classification is relevant for the subsequent action of the Standing Committee and COP under the CITES NCP.

Generally, non-state actors have no triggering capacity at all. Indirectly, however, treaty bodies may gain access to information through alternative channels. This seems to be especially the case in the Nagoya Protocol NCP. There the Secretariat may submit information related to compliance-issues with Article 12 of the Protocol on traditional knowledge associated with genetic resources to which it gained access through 'a directly affected indigenous or local community'. Previously, however, it must have tried to solve the issue among that community and the state concerned. ${ }^{45}$

Once the procedure starts, the Committee assesses whether the Party actually is in noncompliance and, if so, the causes that have led to this situation. To this end, the Committee primarily relies on the information submitted by the treaty bodies and the party itself. Nevertheless, if the circumstances require it, the Committee may also engage in fact-finding or seek expert advice.

Lastly, compliance bodies are bound to a series of procedural safeguards in order to protect the legitimate interests of the parties under scrutiny. These include the right to be heard, i.e., to submit written or oral statements in any stage of the procedure, as well as the proper protection of the confidentiality of sensitive data and the impartiality of the members of the Committee. $^{46}$

\section{III.33.4.2 Public participation}

In past decades, non-state actors - particularly NGOs - have managed to increase their influence in international legal processes. Undoubtedly, a series of MEAs adopted in the UNECE region - especially, the 1998 Aarhus Convention on Access to Information, Public Participation in Decision-Making and Access to Justice in Environmental Matters - are at the cutting edge of public participation standards. ${ }^{47}$ Within biodiversity and nature protection regimes, the only compliance mechanism that equals these standards and confers triggeringcapacity to the public is established under the Bern Convention, which is a regional wildlife

\footnotetext{
${ }^{44}$ See https://cites.org/sites/default/files/eng/prog/Legislation/CITES-NLP-status.pdf (accessed 8 March 2016).

${ }^{45}$ COP-MOP Dec NP-1/4 Annex paras D.9-10.

${ }^{46}$ Montini (2009).

${ }^{47}$ Ebbesson (2007) 685.
} 
protection treaty adopted under the aegis of the Council of Europe. Also the Alpine Convention NCP allows observers to initiate the procedure. ${ }^{48}$ In other regional contexts and, indeed, in the wider global field, public participation in compliance mechanisms spurs considerable anxiety. Significantly, the only (unsuccessful) attempts to trigger the Cartagena Protocol compliance mechanism were made precisely by NGOs. ${ }^{49}$ Governments often portray public participation as jeopardizing the compliance mechanisms' cooperative and nonconfrontational idiosyncrasy. Moreover, non-Western developing countries deeply distrust what they perceive as an over-representation of NGOs from developed countries pursuing West-centric agendas. ${ }^{50}$ In this sense, the recent Nagoya Protocol NCP features a compromise solution, where 'two representatives of indigenous and local communities, at least one from a developing country, nominated by indigenous and local communities, shall serve as observers and shall be entitled to participate in the deliberations of the Committee except in the taking of decisions' ${ }^{51}$

In general, non-state actors play a role as occasional and informal information providers for compliance bodies, whenever they seek independent expertise or the ascertainment of facts. Again, the extents to which treaty bodies rely on them for ascertaining facts vary from one regime to another. The aforementioned collaboration between CITES and TRAFFIC is a remarkable, albeit exceptional example. Also the World Heritage Committee tends to seek information from the wider public when assessing the state of specific sites. ${ }^{52}$ Nevertheless, the general picture in compliance mechanisms of biodiversity regimes is a more modest one. Yet, despite their limited capacity to influence compliance mechanisms in global MEAs, the vigilant attitude of non-state actors is widely acknowledged as incentivizing state-compliance with international commitments. ${ }^{53}$

\section{III.33.4.3 Compliance measures}

Whenever confronted with specific compliance issues, compliance bodies can issue a series of responses ranging from facilitative, compliance-eliciting measures, to 'hard' sanctions.

\footnotetext{
${ }^{48}$ For references of compliance mechanisms, see section 6 below.

${ }^{49}$ UN Doc UNEP/CBD/BS/CC/5/4 (21 November 2008) paras 24-25.

${ }^{50}$ Pitea (2008) 195-197.

${ }^{51}$ UN Doc UNEP/CBD/NP/COP-MOP/DEC/1/4 (2014) Annex para B.2.

${ }^{52} \mathrm{Scott}$ (2012) at 251.

${ }^{53}$ Pitea (2005).
} 
The former include administrative, technical and financial support to non-compliant parties in order to attain an acceptable performance with undertaken commitments. ${ }^{54}$ In combination with granted supportive measures, non-compliant parties are typically encouraged to draw up and implement detailed plans through which compliance is to be regained. ${ }^{55}$

Should this facilitative approach not be effective in a reasonable period of time, the terms of reference of a number of compliance mechanisms also foresee additional measures of a harder, punitive, character. Among the biodiversity regimes that are dealt with in this chapter, these measures range from the issuance of cautions, to last-resort measures such as the removal of deteriorated sites from the lists of the Ramsar Convention ${ }^{56}$ or the WHC, or the issuance of public lists of countries engaged in or facilitating illegal, unreported and unregulated fishing by compliance bodies of RFMOs. ${ }^{57}$ Once again, the most extreme example of sanctions relates to CITES, the Standing Committee of which has a remarkable track record of recommendations for the suspension of commercial trade in CITES species with non-compliant parties. ${ }^{58}$ These latter measures, however, push compliance mechanisms to their limits. On the one hand, their punitive nature runs counter the managerial idiosyncrasy of NCPs and are thus harder to agree on. On the other hand, they also raise a series of long-debated theoretical questions on the relationship and boundaries of compliance procedures with the law of the treaties, ${ }^{59}$ state responsibility ${ }^{60}$ and international adjudication. $^{61}$

More fundamentally, the operation of compliance mechanisms incites a critical reflection from a global sociological perspective. An overall assessment of their functioning reveals that the overwhelming majority of compliance measures - whether facilitative or punitive - have been addressed at developing countries, while one cannot reasonably accept that these have been the only states that have been non-compliant with MEAs. Indeed, as some scholars have

\footnotetext{
${ }^{54}$ Milano (2009) 409.

55 ibid.

${ }^{56}$ On the inherent weaknesses of the Ramsar Convention NCP, however, see Ferrajolo (2011) 252-254.

${ }^{57} \mathrm{Scott}$ (2012) 246.

${ }^{58}$ For a historical record of suspensions of all commercial trade in CITES-listed species from 1985 to 2013, see Sand (2013) at 256.

${ }^{59}$ See generally Koskenniemi (1992); Fitzmaurice and Redgwell (2000); Fitzmaurice (2009).

${ }^{60}$ Pineschi (2009).

${ }^{61}$ On the relationship between compliance mechanisms and adjudicative dispute settlement, see Fitzmaurice and Redgwell (2000); Treves (2009); Scott (2012) 254; and Boyle and Harrison (2013).
} 
pointed out, this assessment clearly hints at structural biases that are hidden behind the underlying managerial mindset. ${ }^{62}$

\section{III.33.5 Final remarks}

Biodiversity regimes reveal a remarkable regulatory heterogeneity, which is due to the multiplicity of layers of interrelated regimes that were established in different historical moments, according to disparate ideologies and approaches. Monitoring and compliance mechanisms, however, provide for some homogeneity among these treaties. The cohesive element is their managerial idiosyncrasy. Certainly, this pragmatic approach is to a great extent responsible for the relative success of international environmental law over the past decades. However, the flipside of it is that despite the enormous administrative, technical and financial effort to implement these regimes, as Klabbers says, 'somehow, compliance seems to be intensely negotiable'. ${ }^{63}$

Future research on monitoring and compliance mechanisms, especially in the field of international biodiversity law, might therefore focus on elucidating empirical conditions and theoretical premises under which they may improve their contribution not only to regimeeffectiveness, but also to the international rule of law. Improving the MEA's institutional arrangements for the protection of common interests and the furtherance of public participation in environmental compliance mechanisms is one avenue. Another path lies in appraising the current and potential interactions between environmental compliance mechanisms and national, as well as international courts. These interactions may contribute to reducing the states' and international institutions' margin of discretion in 'managing' compliance, hence reducing current biases.

\section{III.33.6 Annex: list of compliance mechanisms adopted in biodiversity and nature protection treaties}

III.33.6.1 Compliance mechanisms in the biodiversity regime

- 2000 Cartagena Protocol on Biosafety to the 1992 Convention on Biological Diversity (adopted 29 January 2000, entered into force 11 September 2003) 2226 UNTS 208

\footnotetext{
${ }^{62}$ Klabbers (2007) 996; Sand (2013) 261.

${ }^{63}$ Klabbers (2007).
} 
Art 34; Decision BS-I/7 (2005) Establishment of Procedures and Mechanisms on Compliance under the Cartagena Protocol on Biosafety; Decision BS-II/1 (2006) Rules of Procedure for Meetings of the Compliance Committee; Decision BS-III/1 (2007) Compliance; Decision BS-IV/1 (2007) Compliance; Decision BS-V/1 (2010) Compliance.

- 2010 Nagoya Protocol on Access to Genetic Resources and the Fair and Equitable Sharing of Benefits Arising from Their Utilisation to the Convention on Biological Diversity (adopted 29 October 2010, entered into force 12 October 2014), Art 30; Decision NP-1/4 (2014) Cooperative Procedures and Institutional Mechanisms to Promote Compliance with the Nagoya Protocol and to Address Cases of NonCompliance. $</$ list $>$

III.33.6.2 Compliance mechanisms in sectorial or issue-specific biodiversity and nature protection regimes

- 1971 Convention on Wetlands of International Importance (adopted 2 February 1971, entered into force 21 December 1975) 996 UNTS 245 (Ramsar Convention), Art 6; Recommendation 4.7: Mechanisms for improved application of the Ramsar Convention; Resolution VI.1: Working definitions of ecological character, guidelines for describing and maintaining the ecological character of listed sites, and guidelines for operation of the Montreux Record.

- 1972 UNESCO Convention Concerning the Protection of the World Cultural and Natural Heritage (adopted 16 November 1972, entered into force 17 December 1975) 1037 UNTS 151, Art 11(4).

- 1973 Convention on International Trade in Endangered Species of Fauna and Flora (adopted 3 March 1973, entered into force 1 July 1975) 993 UNTS 243, Arts XII and XIII; Conf 11.3 (RevCOP14) Compliance and Enforcement; Conf 14.3 CITES Compliance Procedures; Conf 11.1 (Rev CoP16) Establishment of Committees.

- 1976 Barcelona Convention for the Protection of the Marine Environment and the Coastal Region of the Mediterranean (adopted 16 February 1976, entered into force 12 February 1978) 1102 UNTS 27 (as amended 10 June 1995, entered into force 9 July 2004), Arts 18 and 27; Decision IG 17/2: Procedures and mechanisms on 
compliance under the Barcelona Convention and its Protocols (2008), as last amended by Decision IG 21/1 (2013).

- 1979 Convention on the Conservation of European Wildlife and Natural Habitats (adopted 19 September 1979, entered into force 1 June 1982) 1284 UNTS 209 (Bern Convention), Arts 13 and 14; Decision T-PVS (93)22 (1993) Implementation of the Bern Convention; Opening and Closing of Files and Follow-up Recommendations.

- 1980 Convention on the Conservation of Antarctic Marine Living Resources (adopted 20 May 1980, entered into force 7 April 1982) 1329 UNTS 47 (CCAMLR), Art XI; Standing Committee on Implementation and Compliance (SCIC) ToR and Organisation of Work agreed at the XXI Meeting of the CCAMLR Commission (2002), XXI (2002) CCAMLR Commission Report, Annex 5, Appendix VII.

- 1991 Convention for the Protection of the Alps (adopted 7 November 1991, entered into force 6 March 1996) 1917 UNTS 135 (Alpine Convention), Arts 5 and 6; Mechanism for Reviewing Compliance with the Alpine Convention and its Implementation Protocols (Doc ACXII/A1), adopted by the 12th Alpine Conference (2012).

- 2001 International Treaty on Plant Genetic Resources for Food and Agriculture (adopted 3 November 2001, entered into force 29 June 2004) 2400 UNTS 303, Arts 19(3)(e) and 21; GB Resolution 2/2011, Annex, Procedures and Operational Mechanisms to Promote Compliance and to Address Issues of Non-Compliance; GB Resolution 9/2013, Rules of Procedure. $</$ list $>$

\section{III.33.6.3 Compliance mechanisms in Regional Fisheries Management Organizations}

- 1966 International Commission for the Conservation of Atlantic Tunas (adopted 14 May 1966, entered into force 21 March 1969) 673 UNTS 63 (ICCAT), Art IX; Recommendation 95-15 Mandate and Terms of Reference adopted by the Commission for the ICCAT Conservation and Management Measures Compliance Committee.

- 1999 Agreement on the International Dolphin Conservation Programme (adopted 15 May 1998, entered into force 15 February 1999), Arts XII and XVI, and Annex VII; 2002 Resolution on the Definition of a Pattern of Infractions. 
- 2000 Convention on the Conservation and Management of Highly Migratory Fish Stocks in the Western and Central Pacific Ocean (adopted 5 September 2000, entered into force 19 June 2004) 2275 UNTS 43, Arts 11, 14 and 25; Western and Central Pacific Fisheries Commission Rules of Procedure (2004).

- 2003 Convention for the Strengthening of the Inter-American Tropical Tuna Commission Established by the 1949 Convention between the United States of America and the Republic of Costa Rica (adopted 13 December 2004, entered into force 10 October 2008) (IATTC) Arts VII (59), XVIII (6) and (10), and Annex 3; 1999 Resolution on the Establishment of a Permanent Working Group on Compliance; 2000 Permanent Working Group on Compliance-Rules of Procedure. $</$ list $>$

\section{Bibliography}

Bodansky D, 'The Legitimacy of International Governance: A Coming Challenge for International Environmental Law?' (1999) 93 American Journal of International Law 526.

Bowman M, 'The Nature, Development and Philosophical Foundations of the Biodiversity Concept in International Law' in C Redgwell and M Bowman (eds), International Law and the Conservation of Biological Diversity (Kluwer 1996) 5.

Boyle A and Harrison J, 'Judicial Settlement of International Environmental Disputes: Current Problems’ (2013) 4 Journal of International Dispute Settlement 245.

Cardesa-Salzmann A, 'Constitutionalising Secondary Rules in Global Environmental Regimes: Non-Compliance Procedures and the Enforcement of Multilateral Environmental Agreements' (2012) 24 Journal of Environmental Law 103.

Chayes A and Handler Chayes A, The New Sovereignty: Compliance with International Regulatory Agreements (Harvard University Press 1995).

Churchill RR and Ulfstein G, 'Autonomous Institutional Arrangements in Multilateral Environmental Agreements: A Little-Noticed Phenomenon' (2000) 94 American Journal of International Law 623.

Ebbesson J, 'Public Participation' in D Bodansky, J Brunnée and E Hey (eds), The Oxford Handbook of International Environmental Law (Oxford University Press 2007) 974. 
Ferrajolo O, 'State Obligations and Non-Compliance in the Ramsar System' (2011) 14 Journal of International Wildlife Law \& Policy 243.

Fitzmaurice M, 'International Environmental Law as a Special Field' (1994) 25 Netherlands Yearbook of International Law 181.

Fitzmaurice M, 'Non-Compliance Procedures and the Law of the Treaties' in T Treves and others (eds), Non-Compliance Procedures and Mechanisms and the Effectiveness of International Environmental Agreements (TMC Asser Press 2009) 453.

Fitzmaurice M and Redgwell C, 'Environmental Non-Compliance Procedures and International Law' (2000) 31 Netherlands Yearbook of International Law 35.

Fodella A, 'Structural and Institutional Aspects of Non-Compliance Mechanisms' in T Treves and others (eds), Non-Compliance Procedures and Mechanisms and the Effectiveness of International Environmental Agreements (TMC Asser Press 2009) 355.

Francioni F, 'Dispute Avoidance in International Environmental Law' in A Kiss, D Shelton and K Ishibashi (eds), Economic Globalization and Compliance with International Environmental Agreements (Kluwer 2003) 229.

French D, 'Finding Autonomy in International Environmental Law and Governance' (2009) 21 Journal of Environmental Law 255.

Handl G, 'Compliance Control Mechanisms and International Environmental Obligations' (1997) 5 Tulane Journal of International and Comparative Law 29.

Klabbers J, 'Compliance Procedures' in D Bodansky, J Brunnée and E Hey (eds), The Oxford Handbook of International Environmental Law (Oxford University Press 2007) 995.

Klabbers J, 'The Commodification of International Law' in H Ruiz Fabri, E Jouannet and V Tomkiewicz (eds), Select Proceedings of the European Society of International Law: Volume 1, 2006 (Hart 2008) 341.

Koskenniemi M, 'Breach of Treaty or Non-Compliance? Reflections on the Enforcement of the Montreal Protocol' (1992) 3 Yearbook of International Environmental Law 123.

Maffei MC, 'Evolving Trends in the International Protection of Species' (1993) 36 German Yearbook of International Law 131. 
Milano E, 'The Outcomes of the Procedure and their Legal Effects' in T Treves and others (eds), Non-Compliance Procedures and the Effectiveness of International Environmental Agreements (TMC Asser Press 2009) 407.

Montini M, 'Procedural Guarantees in Non-Compliance Procedures' in T Treves and others (eds), Non-Compliance Procedures and the Effectiveness of International Environmental Agreements (TMC Asser Press 2009) 389.

Nègre C, 'Responsibility and International Environmental Law' in J Crawford, A Pellet and S Olleson (eds), The Law of International Responsibility (Oxford University Press 2010) 308.

Pineschi L, 'Non-Compliance and the Law of State Responsibility' in T Treves and others (eds), Non-Compliance Procedures and Mechanisms and the Effectiveness of International Environmental Agreements (TMC Asser Press 2009) 483.

Pitea C, 'NGOs in Non-Compliance Mechanisms under Multilateral Environmental Agreements: From Tolerance to Recognition?' in T Treves and others (eds), Civil Society, International Courts and Compliance Bodies (TMC Asser Press 2005) 205.

Pitea C, 'The Legal Status of NGOs in Environmental Non-Compliance Procedures: An Assessment of Law and Practice' in PM Dupuy and L Vierucci (eds), NGOs in International Law: Efficiency in Flexibility? (Edward Elgar 2008) 181.

Rayfuse R, 'Biological Resources’ in Daniel Bodansky, J Brunnée and E Hey (eds), The Oxford Handbook of International Environmental Law (Oxford University Press 2007) 362.

Sand PH, 'Enforcing CITES: The Rise and Fall of Trade Sanctions' (2013) 22 Review of European, Comparative \& International Environmental Law 251.

Scott KN, 'Non-Compliance Procedures and Dispute Resolution Mechanisms under International Environmental Agreements' in D French, M Saul and ND White (eds), International Law and Dispute Settlement: New Problems and Techniques (Hart 2012) 225.

Treves T, 'The Settlement of Disputes and Non-Compliance Procedures' in T Treves and others (eds), Non-Compliance Procedures and Mechanisms and the Effectiveness of International Environmental Agreements (TMC Asser Press 2009) 505.

UNEP-WCMC, Preconditions for harmonization of reporting to biodiversity-related multilateral environmental agreements (2009). Available at 
https://www.cbd.int/cooperation/preconditions-harmonization-unep-wcmc-en-pdf (accessed 31 July 2015).

Wettestad J, 'Monitoring and Verification' in D Bodansky, J Brunnée and E Hey (eds), The Oxford Handbook of International Environmental Law (Oxford University Press 2007) 974.

Wiersema A, 'The New International Law-Makers? Conferences of the Parties to Multilateral Environmental Agreements' (2009) 31 Michigan Journal of International Law 231. 